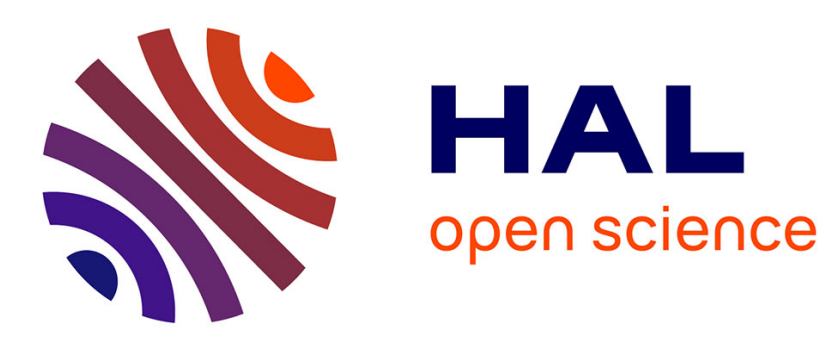

\title{
The Retrieval of Ice-Cloud Properties from Cloud Radar and Lidar Synergy
}

Claire Tinel, Jacques Testud, Jacques Pelon, Robin J. Hogan, Alain Protat, Julien Delanoë, Dominique Bouniol

\section{- To cite this version:}

Claire Tinel, Jacques Testud, Jacques Pelon, Robin J. Hogan, Alain Protat, et al.. The Retrieval of Ice-Cloud Properties from Cloud Radar and Lidar Synergy. Journal of Applied Meteorology, 2005, 44, pp.860-875. 10.1175/JAM2229.1 . hal-00068951

\section{HAL Id: hal-00068951 https://hal.science/hal-00068951}

Submitted on 12 Dec 2020

HAL is a multi-disciplinary open access archive for the deposit and dissemination of scientific research documents, whether they are published or not. The documents may come from teaching and research institutions in France or abroad, or from public or private research centers.
L'archive ouverte pluridisciplinaire HAL, est destinée au dépôt et à la diffusion de documents scientifiques de niveau recherche, publiés ou non, émanant des établissements d'enseignement et de recherche français ou étrangers, des laboratoires publics ou privés. 


\title{
The Retrieval of Ice-Cloud Properties from Cloud Radar and Lidar Synergy
}

\author{
Claire Tinel* and Jacques Testud \\ Centre d'études Terrestre et Planétaires, Institut Pierre Simon Laplace, Paris, France \\ JACQues Pelon \\ Service d'Aéronomie, Institut Pierre Simon Laplace, Paris, France \\ RoBin J. HogAN \\ Department of Meteorology, University of Reading, Reading, United Kingdom \\ Alain Protat, Julien Delanoë, and Dominique Bouniol \\ Centre d'études Terrestre et Planétaires, Institut Pierre Simon Laplace, Paris, France
}

(Manuscript received 19 December 2003, in final form 20 October 2004)

\begin{abstract}
Clouds are an important component of the earth's climate system. A better description of their microphysical properties is needed to improve radiative transfer calculations. In the framework of the Earth, Clouds, Aerosols, and Radiation Explorer (EarthCARE) mission preparation, the radar-lidar (RALI) airborne system, developed at L'Institut Pierre Simon Laplace (France), can be used as an airborne demonstrator. This paper presents an original method that combines cloud radar (94-95 GHz) and lidar data to derive the radiative and microphysical properties of clouds. It combines the apparent backscatter reflectivity from the radar and the apparent backscatter coefficient from the lidar. The principle of this algorithm relies on the use of a relationship between the extinction coefficient and the radar specific attenuation, derived from airborne microphysical data and Mie scattering calculations. To solve radar and lidar equations in the cloud region where signals can be obtained from both instruments, the extinction coefficients at some reference range $z_{0}$ must be known. Because the algorithms are stable for inversion performed from range $z_{0}$ toward the emitter, $z_{0}$ is chosen at the farther cloud boundary as observed by the lidar. Then, making an assumption of a relationship between extinction coefficient and backscattering coefficient, the whole extinction coefficient, the apparent reflectivity, cloud physical parameters, the effective radius, and ice water content profiles are derived. This algorithm is applied to a blind test for downward-looking instruments where the original profiles are derived from in situ measurements. It is also applied to real lidar and radar data, obtained during the 1998 Cloud Lidar and Radar Experiment (CLARE'98) field project when a prototype airborne RALI system was flown pointing at nadir. The results from the synergetic algorithm agree reasonably well with the in situ measurements.
\end{abstract}

\section{Introduction}

Covering permanently almost two-thirds of the earth (Paltridge 1974), clouds reflect solar radiation and ab-

\footnotetext{
* Current affiliation: Centre National d'études Spatiales, Toulouse, France.
}

Corresponding author address: Claire Tinel, CNES, DCT/SI/ MO-BPI 811, 18 av. Edouard Belin, 31401 Toulouse Cedex 9, France.

E-mail: claire.tinel@cnes.fr sorb a significant part of the infrared radiation emitted by the earth. Thus they exert a large influence on our weather and climate. Ice clouds represent $30 \%$ of the global cloud distribution (Riedi et al. 2000), but they currently are not represented correctly in the numerical global and forecast models, mainly because of the incomplete knowledge about their dynamical and physical properties (Cess et al. 1990, 1996). For these reasons one of the goals of the international scientific community is to achieve better information on the microphysical, dynamical, and radiative properties of clouds.

A way to obtain this information is to use combined 
ground, space, or airborne remote sensing instruments. First, combinations of active and passive instruments have been deployed from the ground in the 1990s. Matrosov et al. (1992) used radar and infrared radiometer to retrieve ice-cloud particle sizes and water contents. Mace et al. (1998a) proposed a method combining a radar and an infrared interferometer; Kumagai et al. (2000) combined a cloud radar and a microwave radiometer.

Uttal et al. (1990) and Intrieri et al. (1990) have conducted preliminary comparisons of lidar and backscattering in cirrus clouds. Intrieri et al. (1993) have developed one of the first studies combining radar and lidar backscatter to retrieve cloud properties. Their method employs the wavelength-dependent difference in backscatter between a carbon dioxide lidar (10.6 $\mu \mathrm{m})$, an $\mathrm{X}$-band radar $(3.2 \mathrm{~cm})$, and a $\mathrm{Ka}$-band $\operatorname{radar}(8.6 \mathrm{~mm})$ (among others) to determine the effective radius of icecrystal sizes. Thus they compare the theoretical and observed backscatter coefficients, but they assume that all cloud particles were solid ice spheres and limit the lidar retrievals to an optical depth of 1 . Mace et al. (1998b) used radar and lidar data to describe the cloud structure. These methods use a gate-by-gate correction for the lidar backscatter that becomes unstable once the optical depth becomes larger than 0.2 or 0.3 . Flamant et al. (2000) studied some cirrus cases using a similar method and concluded that the radar-lidar combination had difficulty in retrieving small particles (with an effective radius of less than $20 \mu \mathrm{m}$ ) because of the limited radar sensitivity. Wang and Sassen (2002) recently used a parameterization of ice water content and particle size in a function of integrated instrumental parameters. Other approaches that constrain lidar extinction retrieval from radar information (Donovan and van Lammeren 2001; Donovan et al. 2001; Okamoto et al. 2003), have been developed recently. Those methods overcome the instability of a gate-by-gate correction and use total lidar attenuation as well as the attenuation at each gate.

In this paper, we explore in detail the concept of an original retrieval algorithm combining lidar and radar data [improved from Tinel et al. (2000)] and use it on simulated data and on 1998 Cloud Lidar and Radar Experiment (CLARE'98) measurements. This algorithm is based on the use of a set of power laws, called an inverse model, between integrated microphysical and instrumental parameters. The method presented in this paper is similar to the one presented by Donovan et al. (2001) because they try to find the solution that minimizes variations in the ratio of some power of the radar reflectivity to some power of the lidar attenuation. The difference occurs in the choice of the least fluctuation of one parameter-the retrieved particle size at the far end of the cloud for Donovan et al. (2001) and the particle number concentration for this new method. This method involves the $N_{0}^{*}$ parameter. For a better understanding, a summary of the concept of the "normalized" distribution to describe particle spectra developed by Testud et al. (2001) is explained in section 2. In section 3 the method combining radar reflectivity and lidar backscattering coefficient to retrieve cloud microphysical parameters, such as liquid water and ice water contents, and radiative parameters, such as the effective radius, is described. In section 4 the accuracy of algorithm retrievals is tested in a "blind" test. In section 5 the algorithm is applied to CLARE'98 data, when the first prototype airborne radar-lidar system was flown, and results are discussed.

As shown by Donovan et al. (2001), cloud radar-lidar synergy cannot retrieve an effective radius lower than $10 \mu \mathrm{m}$. This algorithm can be applied to high clouds where the lidar signal is strong enough to penetrate deep into the clouds and midlevel clouds with optical depth smaller than 4.5 (Tinel 2002).

\section{Inverse model for radar and lidar retrieval}

This section describes the concept of "normalized" particle size distribution developed by Testud et al. (2001), which aims to describe as accurately as possible the mean particle spectra. Parameters defining the response of active remote sensing instruments are the radar reflectivity $Z_{e}$, the radar specific attenuation $K$, the lidar backscattering coefficient $\beta_{a}$, and the lidar extinction coefficient $\alpha$. They are by definition proportional to the moments of particle size distribution (PSD). Relationships between those parameters and microphysical parameters relevant to the evaluation of the cloud radiative properties [ice water content (IWC) and effective radius $r_{e}$ of particles] can thus be established.

The physical characterization of an observed cloud PSD raises the following question: What are the best parameters to use to characterize the mean particle size and the shape of the PSD?

The ice water content can be related to the cloud particle size distribution $N(D)$, where $D$ is defined as the particle diameter. Its expression is complex because it depends on particle density and shape. We will use hereinafter the formulation of Francis et al. (1998), who calculate the IWC from the microphysical observations as

$$
\mathrm{IWC}=\frac{\pi \rho_{w}}{6} \int_{0}^{\infty} N\left(D_{\mathrm{eq}}\right) D_{\mathrm{eq}}^{3} d D_{\mathrm{eq}}
$$


where $D_{\text {eq }}$ is the "equivalent melted diameter" (the diameter that the ice particle would have if it were completely spherical and with a constant mass density), $\rho_{w}$ is the density of water, and $N\left(D_{\text {eq }}\right) d D_{\text {eq }}$ is the number concentration of particles with diameters between $D_{\text {eq }}$ and $D_{\text {eq }}+d D_{\text {eq }}$. The $D_{\text {eq }}$ is empirically related to the cross-sectional area $A$ of the ice particle observed by the $2 \mathrm{D}$ probe through (Francis et al. 1998)

$$
\begin{aligned}
& D_{\text {eq }}=1.097 A^{0.50} \text { for } A \leq 0.0052 \mathrm{~mm}^{2} \text { and } \\
& D_{\text {eq }}=0.615 A^{0.39} \text { for } A>0.0052 \mathrm{~mm}^{2} .
\end{aligned}
$$

Those relations were obtained from the 1993 European Cloud Radiation Experiment (EUCREX'93) in situ data when midlatitude cirrus clouds were sampled by 2D probes.

The characterization of the mean particle size is more difficult. McFarquhar and Heymsfield (1998) reviewed the different expressions of effective radii of particles according to their shape and phase. In our paper, the general form defined by Francis et al. (1994) is used:

$$
r_{e}=(3 \times \mathrm{IWC}) /\left(2 \rho_{i} \alpha\right),
$$

where $\alpha$ is the optical extinction and $\rho_{i}$ is the density of ice, equal to $0.917 \mathrm{~g} \mathrm{~cm}^{-3}$. In what follows, the mean particle size is characterized by the "mean volumeweighted diameter" (usually referred to as the "mean volume diameter" in the literature), defined as

$$
D_{m}=M_{4} / M_{3},
$$

where $M_{4}$ and $M_{3}$ denote the fourth and third moment of the PSD in $D_{\text {eq }}$ for ice particles. Using the previous definitions, the general expression of the PSD (Testud et al. 2001) is defined as

$$
N\left(D_{\mathrm{eq}}\right)=N_{0}^{*} F\left(D_{\mathrm{eq}} / D_{m}\right),
$$

where $N_{0}^{*}$ is the normalization parameter of the particle concentration, $D_{m}$ is the normalization parameter of the particle diameter, and $F(X)$ is the "normalized PSD" describing the "intrinsic" shape of the PSD (noting $\left.X=D_{\text {eq }} / D_{m}\right)$. Here $N_{0}^{*}$ is calculated using IWC and $D_{m}$, which are calculated from the moments of the PSD:

$$
N_{0}^{*}=\frac{4^{4}}{\pi \rho_{w}} \frac{\mathrm{IWC}}{D_{m}^{4}}
$$

(see Testud et al. 2001), where $\rho_{w}$ is water density $\left(=10^{6}\right.$ $\left.\mathrm{g} \mathrm{m}^{-3}\right)$. Here, $N_{0}^{*}$ is physically interpreted as being equal to the value of the $N_{0}$ parameter from an exponential distribution with the same IWC and $D_{m}$.

In situ data have been collected by aircraft during CLARE'98, which took place in England in the autumn of 1998 (Illingworth et al. 1999) and the 1999
Cloud Airborne Investigation by Radar and Lidar (CARL'99), which took place in France in the spring of 1999 (Pelon et al. 2001).

CLARE'98 was devoted to the characterization of the microphysical, radiative, and dynamic properties of nonprecipitating clouds. For this purpose a groundbased combination of cloud radar, lidar, and radiometers has been deployed, as well as airborne instrumentation, including in situ microphysics and active remote sensing sampling. The C130 aircraft from the Met Office was equipped with forward-scattering spectrometer probes (FSSP) and 2D cloud (2D-C) and 2D precipitation (2D-P) probes. The aircraft was flying in liquid-, ice-, and mixed-phase clouds. In this dataset, nine legs over 3 days have been considered: eight flights on 14 and 20 October (mixed-phase clouds) and one leg (cirrus clouds) on 21 October 1998. In situ measurements have been made at different temperatures $\left(-7^{\circ},-10^{\circ}\right.$, $-14^{\circ}$, and $-31^{\circ} \mathrm{C}$ ); approximately $84 \mathrm{~min}$ of ice-cloud data with an integration time of $5 \mathrm{~s}$ have been extracted for our analysis.

The CARL'99 campaign was devoted to the investigation of ice-cloud properties and involved groundbased lidar, radar, and radiometric measurements, as well as in situ measurements from airborne probes. The Merlin IV aircraft from Météo France was equipped with FSSP, 2D-C, and 2D-P probes from the GKSS (Institute for Atmospherics Physics, in Germany). On 29 April and 4 May 1999, the aircraft was flying in cirrus clouds with respective temperatures of $-36^{\circ}$ and $-21^{\circ} \mathrm{C}$. Sampled data were mainly constituted of small aggregates. This dataset corresponds to $130 \mathrm{~min}$ of data (integration time $10 \mathrm{~s}$ ) in our analysis.

This study concerns midlatitude ice clouds. Studies using in situ microphysical data from other field campaigns (midlatitude and tropical experiments) are also being performed at the Centre d'études Terrestres et Planétaires (CETP) and involve a global dataset of more than $150 \mathrm{~h}$.

If $M_{i}$ is defined as the $i$ th moment of the PSD [ $M_{i}=$ $\left.\int N\left(D_{\mathrm{eq}}\right) D_{\mathrm{eq}}^{i} d D_{\mathrm{eq}}\right]$ and $\xi_{i}$ as the $i$ th moment of the normalized distribution $\left[\xi_{i}=\int F(X) X^{i} d X\right], M_{i}$ can be rewritten, using Eq. (5), as

$$
M_{i}=\int N_{0}^{*} F\left(D_{\mathrm{eq}} / D_{m}\right) D_{\mathrm{eq}}^{n} d D_{\mathrm{eq}}=N_{0}^{*} D_{m}^{i+1} \xi_{i}
$$

Thus the various $M_{i}$ moments can be related to each other with relations that are independent from the PSD shape:

$$
\frac{M_{i}}{N_{0}^{*}}=\xi_{i} \xi_{j}^{-(i+1 / j+1)} \frac{M_{j}^{(i+1 / j+1)}}{N_{0}^{*}} .
$$


The data described above have been used to calculate the various PSD moments and thus microphysical parameters (IWC, $D_{m}, N_{0}^{*}$ ) and parameters related to radar and lidar (equivalent reflectivity $Z_{e}$, radar attenuation $K$, and optical extinction $\alpha$ ). At $94 \mathrm{GHz}$ the effect of Mie scattering is to reduce the reflectivity of the larger particles below that predicted by Rayleigh theory, with the result that the mode in the reflectivityweighted size distribution typically lies between 0.4 and $2 \mathrm{~mm}$ in diameter. This ensures that statistical sampling issues are not a concern when calculating 94-GHz reflectivity from aircraft size spectra. The 2D-P probe measures particles of diameter up to $6.4 \mathrm{~mm}$, and, from the sample volumes given by Heymsfield and Parrish (1978), a volume of $0.65 \mathrm{~m}^{3}$ would be sampled in the 5-s integration interval used in CLARE'98. On average, over 800 particles between 0.4 and $2 \mathrm{~mm}$ were sampled every $5 \mathrm{~s}$, providing a more-than-adequate sample from which to calculate reflectivity. Both $Z_{e}$ and $K$ are calculated in the Mie scattering:

$$
Z_{e}=\frac{\lambda^{4} 10^{18}}{\pi^{5}\left|K_{w}\right|^{2}} \int N(D) \sigma_{r}(\lambda, D) d D,
$$

where $\left|K_{w}\right|^{2}$ is the dielectric factor of water $(=0.17$ for ice; Lhermitte 1987), $\sigma_{r}$ is the particle backscattering cross section, and $D$ is the particle diameter measured by the probes, and

$$
K=\frac{10^{4}}{\ln 10} \int N(D) \sigma_{a}(\lambda, D) d D,
$$

where $\sigma_{r}$ is the particle attenuation cross section. Optical extinction is proportional to the second moment of the PSD:

$$
\alpha=\frac{\pi}{2} \int N(D) D^{2} d D,
$$

where it is assumed that the lidar wavelength is small in comparison with the particle size and the geometric optics approximation can be applied.

Figure 1a shows the equivalent reflectivity $Z_{e}$ (calculated for a $95-\mathrm{GHz}$ radar) versus the IWC. If $Z_{e}$ and IWC are normalized by $N_{0}^{*}$, a much more stable relationship that can be reasonably parameterized as in Eq. (8) is obtained (see Fig. 1b):

$$
\mathrm{IWC}=p\left(N_{0}^{*}\right)^{1-q} Z_{e}^{q} .
$$

As can be seen in Fig. 1a, a curvature in the powerlaw graphic representation appears when $\left(Z / N_{0}^{*}\right)>10^{8}$. This increase in slope observed in this domain is due to Mie effects (Van de Hulst 1957) that appear when particles size $D$ increases, especially when $D / \lambda>0.08$ (Battan 1973). This corresponds to $D>250 \mu \mathrm{m}$ for a 95 -
$\mathrm{GHz}$ radar. This makes it necessary to make a segmentation depending on $D_{m}$ values in the establishment of the power-law relationships.

The determination of similar relationships between the other integrated and microphysical parameters has then been established from in situ microphysical parameters that were recorded during CLARE'98 and CARL'99 (Tinel 2002). They can be expressed as

$$
\begin{aligned}
& \text { IWC }=c\left(N_{0}^{*}\right)^{1-d} K^{d} \text { and } \\
& \text { IWC }=e\left(N_{0}^{*}\right)^{1-e} \alpha^{f},
\end{aligned}
$$

which allows one to derive relationships between the integrated parameter themselves as

$$
\begin{aligned}
K & =a\left(N_{0}^{*}\right)^{1-b} Z_{e}^{b}, \\
\alpha & =m\left(N_{0}^{*}\right)^{1-n} K^{n}, \quad \text { and } \\
\alpha & =s\left(N_{0}^{*}\right)^{1-t} Z_{e}^{t} .
\end{aligned}
$$

Table 1 represents the values obtained for the different relationships applied to three $D_{m}$ domains defined to be in the Rayleigh scattering regime $\left(D_{m} \leq 175 \mu \mathrm{m}\right)$ and in the non-Rayleigh regime-values for $D_{m}>175$ $\mu \mathrm{m}$ and corresponding to $D_{m}>400 \mu \mathrm{m}$ were differentiated to separate the scattering regimes. The three domains are specified on Fig. $1 b$.

\section{Description of the radar-lidar synergetic algorithm}

In this section the mathematical formulation of a synergetic algorithm for radar and lidar is developed. In a dataset, common areas, where measurements from both a radar and a lidar are available, have to be selected for the analysis. This method is applicable to ice clouds, because the inverse model described in the previous section has been derived for ice clouds. However, this algorithm could, in principle, be used for other cloud types, provided that a specific inverse model is developed and introduced in the algorithm. In addition, this formulation is valid for ground-based, airborne, or spaceborne applications.

\section{a. Radar measurements}

The radar does not measure the true reflectivity $Z_{e}$, but an attenuated reflectivity $Z_{a}$ subject to the two-way path attenuation because of the attenuation at $95 \mathrm{GHz}$. Reflectivities $Z_{a}$ and $Z_{e}$ are related through

$$
Z_{a}=Z_{e} \times 10^{-0.2 \int_{0}^{r} K(s) d s},
$$

where $K\left(\mathrm{~dB} \mathrm{~km}^{-1}\right)$ is the specific attenuation and $r$ is the distance from the radar to the measurement alti- 


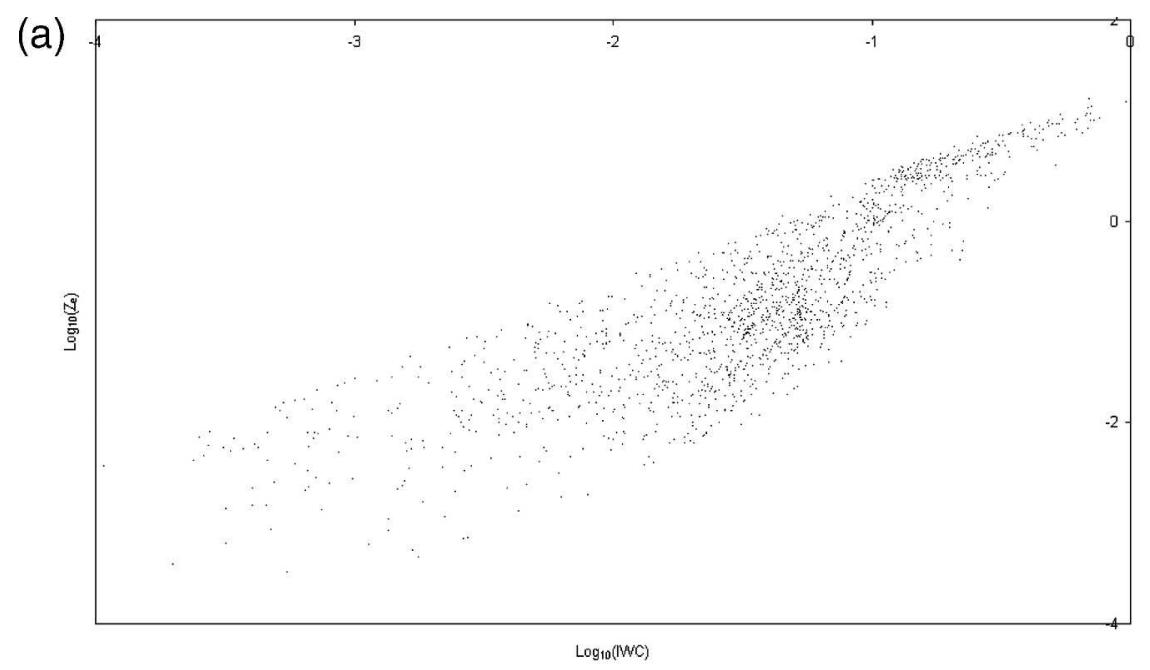

(b)

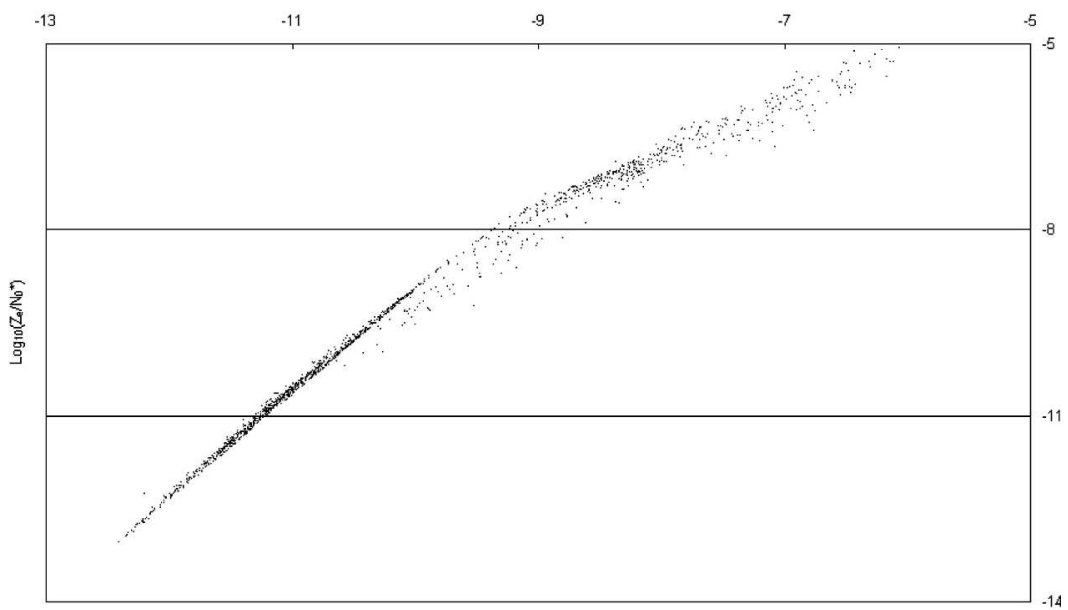

Logio( (INC N $\left.N_{0}^{*}\right)$

Fig. 1. Illustration of (a) IWC $\left(\mathrm{g} \mathrm{m}^{-3}\right)$ vs $Z_{e}\left(\mathrm{~mm}^{6} \mathrm{~m}^{-3}\right)$ and (b) IWC $\left(\mathrm{g} \mathrm{m}^{-3}\right) / N_{0}^{*}\left(\mathrm{~m}^{-4}\right)$ vs $Z_{e}\left(\mathrm{~mm}^{6} \mathrm{~m}^{-3}\right) / N_{0}^{*}\left(\mathrm{~m}^{-4}\right)$ (for a $95-\mathrm{GHz}$ radar) in a logarithmic scale for the CLARE'98/ CARL'99 microphysical dataset for temperatures varying from $-36^{\circ}$ to $-7^{\circ} \mathrm{C}$. In (b), the three $D_{m}$ domains (defined in section 2) are specified as follows: the lowest panel is $175 \mu \mathrm{m}$ $>D_{m}$, the middle panel is $175 \mu \mathrm{m}<D_{m}<400 \mu \mathrm{m}$, and the top panel is $D_{m}>400 \mu \mathrm{m}$.

tude. Variables $Z$ and $K$ are usually related in the literature through a power-law relationship:

$$
K=a^{\prime} Z^{b^{\prime}} .
$$

This power law is valid along the path; it assumes that the radar beam goes all of the way through the same type of particles. Under this assumption, Hitschfeld and Bordan (1954) were the first to derive the exact solution of the inversion of the solution, expressed as

$$
Z_{e}(r)=\frac{Z_{a}(r)}{\left[1-a^{\prime} I(0, r)\right]^{1 / b^{\prime}}},
$$

TABLE 1. Coefficients of the power-law relationships corresponding to the three $D_{m}(\mu \mathrm{m})$ domains derived from in situ microphysical measurements collected by aircraft during CLARE'98 and CARL'99.

\begin{tabular}{lcccccccccccc}
\hline \hline $\begin{array}{c}D_{m}(\mu \mathrm{m}) \\
\text { domain }\end{array}$ & $a$ & $b$ & $c$ & $d$ & $e$ & $f$ & $m$ & $n$ & $p$ & $q$ & $s$ & $t$ \\
\hline$D_{m}>400$ & $2.620 \times 10^{-3}$ & 1.028 & 0.029 & 0.742 & 0.351 & 1.104 & 0.102 & 0.671 & $3.598 \times 10^{-4}$ & 0.764 & $1.980 \times 10^{-3}$ & 0.690 \\
$175<D_{m}<400$ & $8.890 \times 10^{-7}$ & 0.594 & 0.102 & 0.793 & 0.613 & 1.135 & 0.180 & 0.693 & $1.620 \times 10^{-6}$ & 0.471 & $1.222 \times 10^{-5}$ & 0.415 \\
$D_{m}<175$ & $2.010 \times 10^{-7}$ & 0.547 & 0.407 & 0.407 & 1.019 & 1.164 & 0.314 & 0.710 & $9.304 \times 10^{-7}$ & 0.459 & $6.634 \times 10^{-6}$ & 0.395 \\
\hline
\end{tabular}


where

$$
I(0, r)=0.46 b^{\prime} \int_{0}^{r} Z_{a}^{b^{\prime}}(s) d s .
$$

This solution is numerically unstable, as recognized by the authors themselves. It allows the correction from the attenuation as long as the value of the attenuation is weak. When this value increases, however, the algorithm tends to diverge as the value of the denominator tends to 0 . The solution of the equation is also subject to the values of $a^{\prime}$ and $b^{\prime}$, which increases its instability.

Equation (20) may be reformulated with respect to the attenuation in the following manner (Testud et al. 1996):

$$
\begin{aligned}
& K(r)= \\
& \frac{K\left(r_{0}\right) N_{0}^{*}(r)^{1-b} Z_{a}^{b}(r)}{N_{0}^{*}\left(r_{0}\right)^{1-b} Z_{a}^{b}\left(r_{0}\right)+0.46 b K\left(r_{0}\right) \int_{r}^{r_{0}} N_{0}^{*}(s)^{1-b} Z_{a}^{b}(s) d s},
\end{aligned}
$$

where $r_{0}$ is the far-end reference bound $\left(\mathrm{r}<\mathrm{r}_{0}\right)$ and rewriting Eq. (20) in this manner allows us to obtain a stable scheme. We will see later how this boundary is determined in the proposed algorithm. The interest of this formulation is that it provides an expression for a $K$ profile not subject to the radar calibration.

\section{b. Lidar measurements}

In a similar way, the lidar does not measure the true backscattering coefficient, but an apparent backscattering coefficient $\beta_{a}$ that is related to $\beta_{e}$ through

$$
\beta_{a}=\beta_{e} \exp \left[-2 \int_{0}^{r} \alpha(s) d s\right]\left(\mathrm{km}^{-1} \mathrm{sr}^{-1}\right),
$$

where $\alpha\left(\mathrm{km}^{-1}\right)$ is the extinction coefficient. The assumption of a linear law between $\alpha$ and $\beta_{e}$ is generally made:

$$
\beta_{e}=k \alpha .
$$

The problem posed by the inversion of Eq. (22) is the same as that posed by the inversion of Eq. (20). Klett (1981) gave the exact solution of this inversion:

$$
\beta_{e}(r)=\frac{\beta_{a}(r)}{1-2 \int_{r}^{r_{0}}\left[\beta_{a}(s) / k(s)\right] d s} .
$$

As in Eq. (20), this expression of the true backscattering coefficient is numerically unstable because of the divergence when the denominator tends to zero. This solution does not impose to meet the same type of par- ticles along the lidar beam, and $k$ can vary with distance.

The Klett solution may be also reformulated as a stable expression in terms of the extinction coefficient at the far side of the cloud $\alpha\left(r_{0}\right)$ :

$$
\alpha(r)=\frac{\alpha\left(r_{0}\right) \beta_{a}(r)}{\beta_{a}\left(r_{0}\right)+2 \alpha\left(r_{0}\right) \int_{r}^{r_{0}} \beta_{a}(s) d s},
$$

where $r_{0}$ is the far-end reference bound $\left(r<r_{0}\right)$. As for the radar, it does not depend on the instrument calibration. Following the Klett assumption, $k$ is assumed to be constant along the lidar beam. Because $k$ depends on particle size, shape, and orientation, we assume that we have the same type of particles along the beam. This assumption has no effect on the parameter retrieval, as will be shown in section 4b. Its drawback is that it is subject to the determination of $\alpha$ at the reference boundary, which may not be accurately known. To overcome this problem, an iterative procedure is developed to combine radar and lidar data to derive the reference extinction coefficient, which is described hereinafter.

\section{c. Determination of boundary values}

Although we have seen that both (radar and lidar) inversions need to be performed from the far end of the measurement area, it is possible to constrain radar and lidar measurements in relation to each other to derive the boundary values.

Equations (21) and (25) respectively depend on $K\left(r_{0}\right)$ and $\alpha\left(r_{0}\right)$. The following integral constraint along the path of both instrument beams is used to determine those two entities:

$$
\int_{r_{1}}^{r_{0}} \alpha(s) d s=m \int_{r_{1}}^{r_{0}} N_{0}^{*(1-n)}(s) K^{n}(s) d s .
$$

This constraint expresses the consistency of $K(r)$ and $\alpha(r)$ profiles with the power-law relationship obtained by the inverse model described in section 2 . Here, $r_{0}$ and $r_{1}$ are the extreme heights at which lidar and radar signals are both available; $r_{0}$ is the farthest measurement point from the instruments, whereas $r_{1}$ is the nearest one. A function is introduced to stabilize the iterative process of the algorithm that is defined with

$$
f(r)=\frac{N_{0}^{*}(r)}{\overline{N_{0}^{*}}},
$$

where $\overline{N_{0}^{*}}$ is the mean $N_{0}^{*}$ along the profile.

Replacing $K(r)$ from Eq. (21) and $\alpha(r)$ from Eq. (25) and Eq. (16), an implicit equation in $\alpha\left(r_{0}\right)$ is obtained that can be written as 


$$
\alpha\left(r_{0}\right)=\frac{\beta_{a}\left(r_{0}\right)}{2 \int_{r_{0}}^{r_{1}} \beta_{a}(s) d s}\left[\exp \left(2 \frac{\alpha\left(r_{0}\right)}{f\left(r_{0}\right)^{1-n}} \int_{r_{0}}^{r_{1}} f(s)^{1-n}\left\langle\frac{f(s)^{1-b} Z_{a}^{b}(s)}{f(s)^{1-b} Z_{a}^{b}\left(r_{0}\right)+\left\{\frac{\alpha\left(r_{0}\right)}{m\left[f\left(r_{0}\right) \bar{N}_{0}^{*}\right]^{1-n}}\right\}^{1 / n} I\left(s, r_{0}\right)}\right\rangle^{n} d s\right)-1\right],
$$

where

$$
I\left(s, r_{0}\right)=0.46 b \int_{s}^{r_{0}} f(r)^{1-b} Z_{a}^{b}(r) d r .
$$

The algorithm is initialized with a constant value of $N_{0}^{*}\left(=10^{10}\right)$ and $f(r)=1$ that allows a computation of the first value of $\alpha\left(r_{0}\right)$. Then, a new one is determined by solving Eq. (28) that allows the retrieval of a new extinction profile. Because this algorithm is suitable for ice clouds and because the radar attenuation is negligible in ice (mean value of $10^{-2} \mathrm{~dB} \mathrm{~km}^{-1}$ ), the retrieval of the $K(r)$ profile may be unstable because of the low values of the radar attenuation. Thus, a new $N_{0}^{*}(r)$ profile is calculated from optical extinction and $Z_{a}(r)$ [instead of $Z_{e}(r)$ because we assume that $\left.Z_{a}(r) \approx Z_{e}(r)\right]$, and then a new profile of $f(r)$. The process is finally iterated until the following convergence criterion based on the $\alpha\left(r_{0}\right)$ value is satisfied: $\left|\alpha_{i+1}\left(r_{0}\right)-\alpha_{i}\left(r_{0}\right)\right| \leq 10^{-3}$ $\mathrm{km}^{-1}$. The algorithm usually converges in less than 10 iterations.

Once the final $N_{0}^{*}$ vertical profile is obtained, it is possible to retrieve the ice water content profile using Eq. (12). Then, Eq. (3) is used to retrieve the particle effective radius by combining IWC and $\alpha$. The coefficients of the power-law relationships used in the first step of the retrieval process are those corresponding to middle-sized particles $\left(175 \mu \mathrm{m}<D_{m}<400 \mu \mathrm{m}\right)$. The retrieval of IWC and $N_{0}^{*}$ in the convergence process allows us to calculate a new mean $D_{m}$ along the profile, and the coefficients corresponding to this mean value (from Table 1) are used in the next step. The criteria convergence used for the retrieval of $\alpha$ implies a relative error in the retrieval of IWC that is lower than $12 \%$ for $\alpha \geq 0.01 \mathrm{~km}^{-1}$.

This retrieval algorithm aims to find the $\alpha\left(r_{0}\right)$ value (or, equivalent, the optical depth or the $K$ profile) that, when radar and lidar are combined, produces the $N_{0}^{*}$ profile that changes least with height. Because it is physically reasonable to assume that the concentration is fairly consistent as particles fall, the linking constraint between extinction profile and attenuation profile is a powerful constraint.

\section{Application of the algorithm to a blind test}

As mentioned in the introduction, one of the major unknowns in forecasting climate change concerns the radiative impact of clouds. To reduce this uncertainty, the international scientific community is presently designing two space missions: Earth, Clouds, Aerosols, and Radiation Explorer [EarthCARE; the European Space Agency (ESA)-National Space Development Agency (under consideration)] and "CloudSat" [the National Aeronautics and Space Agency (NASA)Canadian Space Agency]-Cloud-Aerosol Lidar and Infrared Pathfinder Satellite Observations [(CALIPSO); NASA-Centre National d'études Spatiales (CNES)]; CloudSat-CALIPSO is slated to be launched in the spring of 2005. The development and validation of the radar-lidar algorithm is naturally done in the framework of the preparation for these two missions. The validation of the algorithm has been conducted with a "blind test" exercise funded by ESA within the framework of EarthCARE mission performance studies. The goal of this test was to apply the synergetic algorithm on a set of data processed by satellite instruments. Several algorithms were involved in this test for intercomparison purposes.

\section{a. Blind-test scenario}

A complete description of the blind-test conditions, results, and comparisons is given in Hogan et al. (2004, manuscript submitted to J. Atmos. Oceanic Technol.). We will concentrate here on the results obtained with our algorithm. A short presentation on the blind-test conditions is provided. The dataset (including five vertical profiles of various parameters of interested as described below) was initially built by R. J. Hogan of the University of Reading from in situ data collected by the Met Office C-130 aircraft during five Lagrangian descents in frontal clouds around the British Isles. The aircraft was equipped with Particle Measuring Systems, Inc., (PMS) 2D cloud and precipitation probes (diameter range $25-6400 \mu \mathrm{m}$ ), and the ice particle size distributions binned by cross-sectional area were used to calculate the five vertical profiles (for five Lagrangian descents; thus, 25 profiles in total): visible extinction coefficient $\alpha$, IWC, effective radius $r_{e}$, radar reflectivity factor at $94 \mathrm{GHz}$ (as seen from space), and lidarattenuated backscatter (as seen from space). For each of the lidar-attenuated backscatter profiles, two profiles of extinction-to-backscatter ratio $k$ were used (using hypothetic but consistent values)—one constant with 

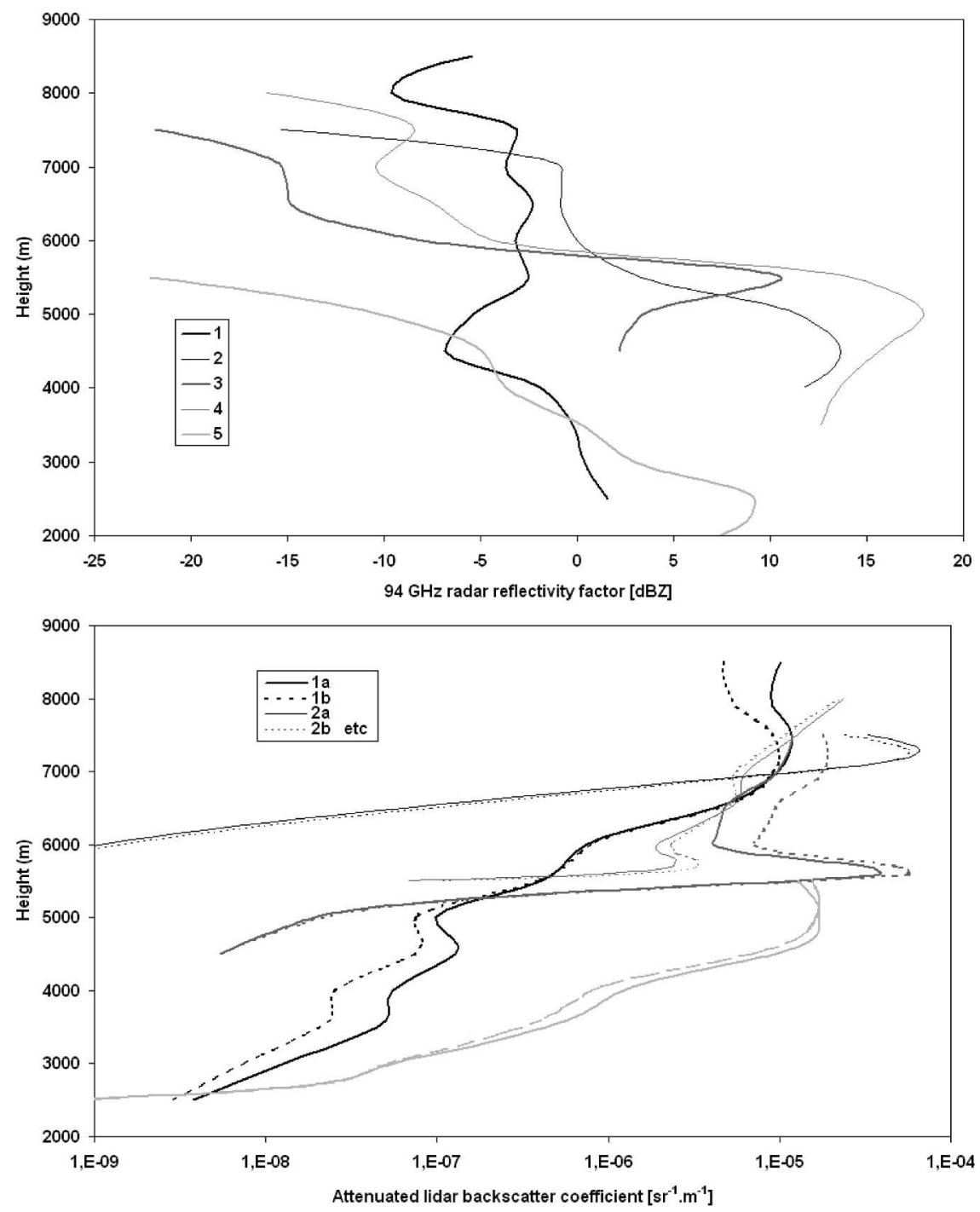

FIG. 2. (top) Apparent cloud radar reflectivity and (bottom) backscattering lidar coefficient profiles as seen from space and derived from in situ measurements; "a" profiles have fixed $k$, and "b" profiles have variable $k$. In the bottom panel, 1,E-09 translates to $1.0 \times 10^{-9}$, etc.

height and the other varying with height over approximately a factor of 2 , similar to the range found by Ansmann et al. (1992). Multiple scattering has not been taken into account in this simulation.

Figure 2 shows the 5 synthetic reflectivity (top panel) and 10 synthetic backscatter profiles (bottom panel; profiles labeled "a" have constant $k$, and profiles labeled "b" have varying $k$ with height), respectively, that were applied in the retrieval algorithm. No information on the $k$ values had been provided before applying the synergetic algorithm to the synthetic profiles.

\section{b. Results}

Without having any information on the microphysical profiles built from in situ microphysical data, the synergetic algorithm has been applied to the simulated apparent reflectivity and lidar backscatter profiles to retrieve IWC and $r_{e}$ profiles. Figures 3-5 show the visible extinction coefficient, ice water content, and effective radius profiles (only for three of the five profiles to provide easier viewing; retrieval accuracies for profiles 2 and 4 are similar to the accuracies for profiles 3 and 5) initially built from the direct profile simulation and the corresponding values blindly retrieved by the algorithm. For each profile, there are two retrievals corresponding to the different $k$ profiles used in the direct profile simulation (constant or varying with height). It is interesting to see that the retrievals in the case of $k$ constant with height (Figs. 3a, 4a, and 5a) are fairly close to the true profiles in most cases, when the re- 

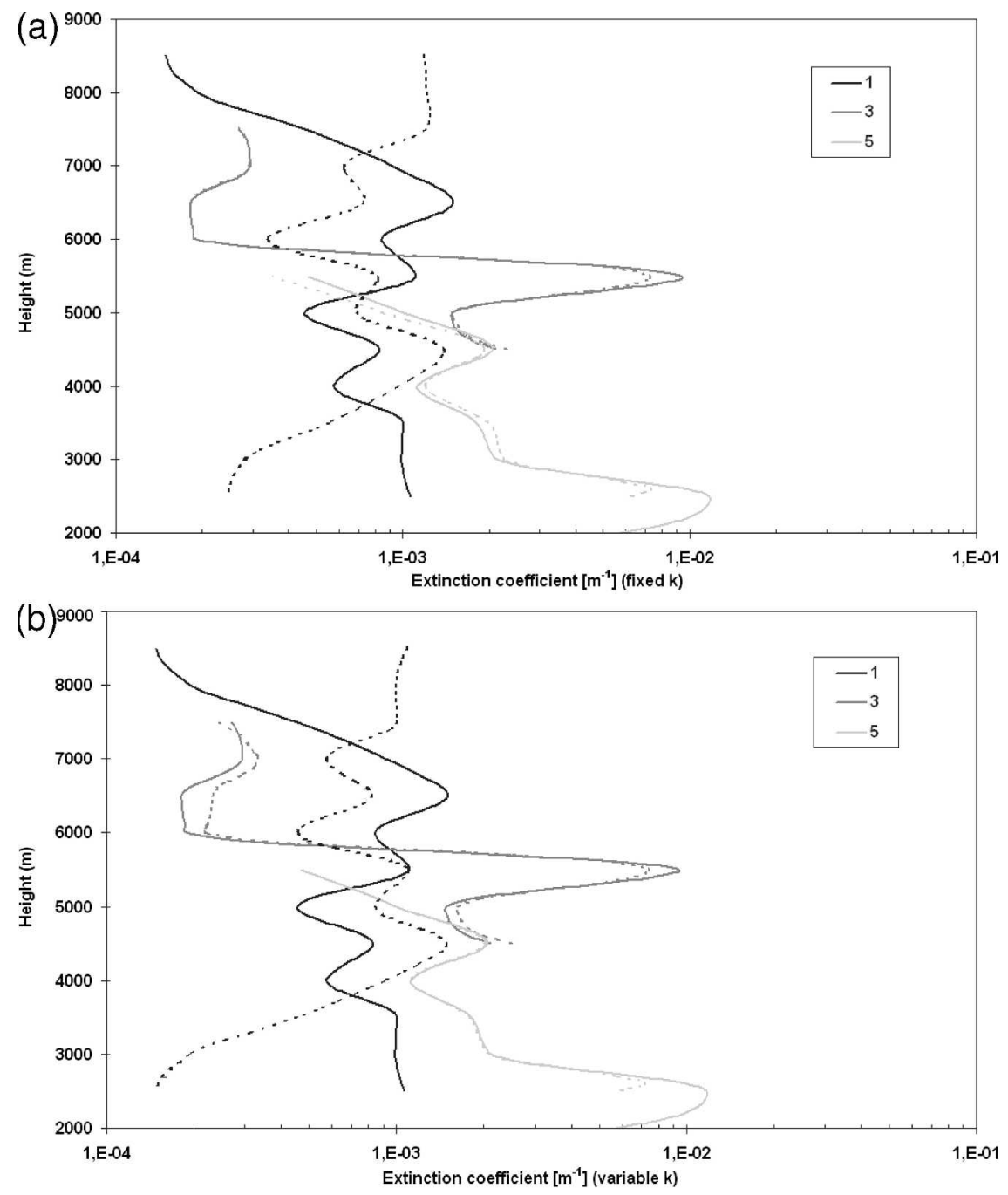

FIG. 3. Realistic (solid lines) and retrieved (dotted lines) visible extinction coefficient derived from the blind test, with (a) fixed $k$ and (b) variable $k$.

trieved profiles in the case of $k$ varying with height are slightly different from the true profiles (Figs. 3b, 4b, and $5 \mathrm{~b}$ ). Mean biases are less than $10 \%$ in most of the cases, which reflects the independence of the algorithm from the value of the mean $k$ profile and its small sensitivity to a variation in $k$. IWC and $r_{e}$ are retrieved well in all cases except for profile 1 , for which retrieved parameters are clearly underestimated. This underestimation is due to the Mie effects that occur at $94 \mathrm{GHz}$ (Van de Hulst 1957). Better accounting for these effects in the inverse model will reduce their impact even if presence of bias is unavoidable: Mie effects mean that reflectivity becomes a similar moment of the size distribution as extinction and so ability to retrieve particle size is lost. Also, there is density dependence at Mie scatter. Because of the power-law relationships, a bias in the retrieved extinction parameter unavoidably brings corresponding bias in the retrieved ice water content. This bias is compensated in the retrieved effective radius due to Eq. (3), as shown in Fig. 4.

Figures 3-5 show that the retrieved reference values at the bottom of each profile (in the lowest few hundred meters) are different from the true values. This difference is due to the hypotheses made in the use of the mathematical integral formulation [Eq. (26)]. Even if there is some uncertainty in the retrieval of $\alpha\left(r_{0}\right)$ (implying disagreement of the retrieved profiles at the lowest boundary for an airborne or spaceborne platform as seen on Fig. 4), the integral formulation allows us to retrieve profiles that are reasonably close to the true ones above it. This situation is due to the increasing contribution of the optical depth, which reduces the error due to the reference.

Figure 6 shows the $N_{0}^{*}$ profiles retrieved by the algo- 

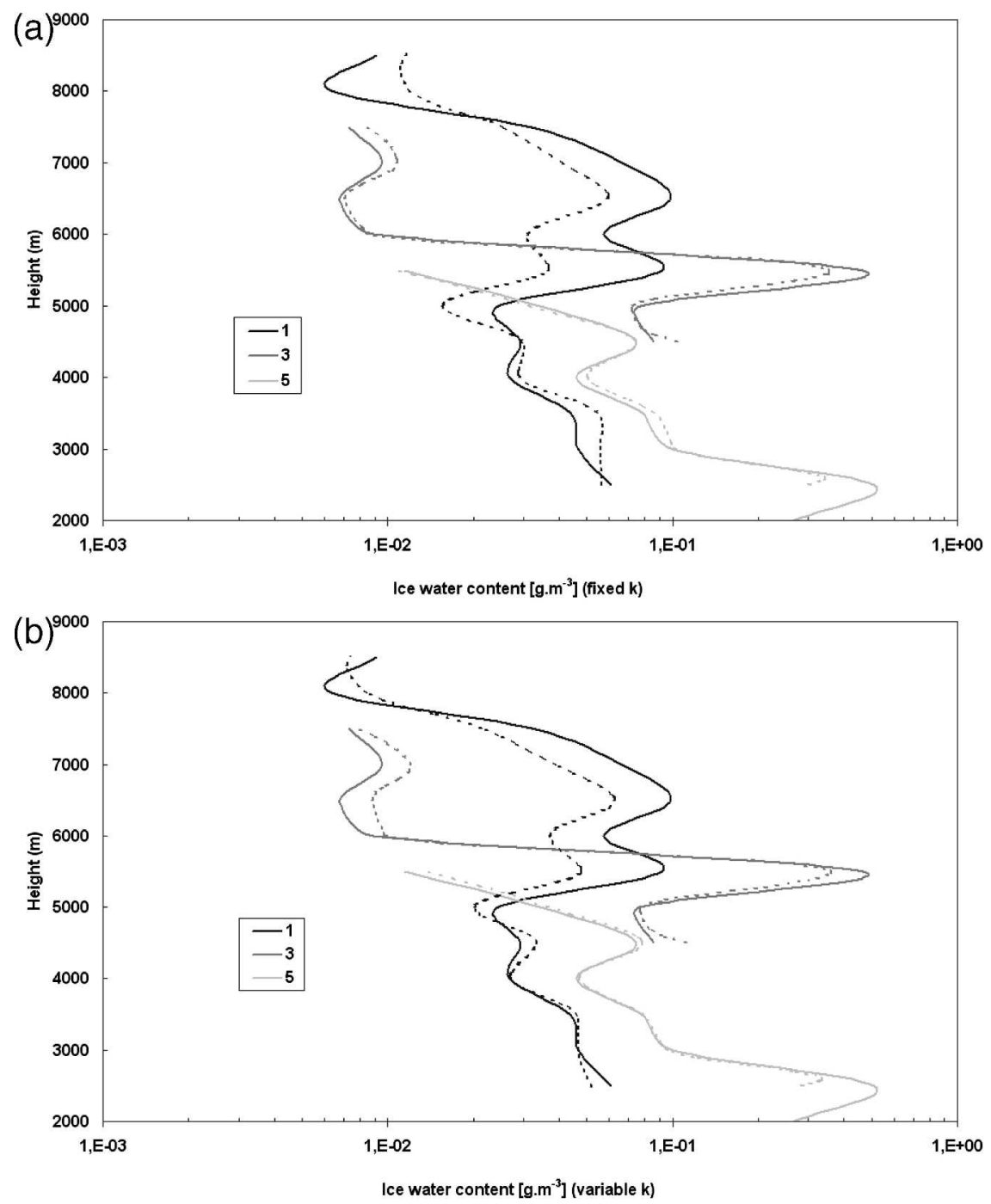

FIG. 4. Realistic (solid lines) and retrieved (dotted lines) ice water content derived from the blind test, with (a) fixed $k$ and (b) variable $k$.

rithm from the simulated radar and lidar measurements (dotted lines) for $k$ constant together with the "realistic" $N_{0}^{*}$ profiles calculated directly from the aircraft size distributions (solid lines). The implication is that this representation mainly depends on coefficients used in the power-law relationships. It appears that $N_{0}^{*}$ may vary by two orders of magnitude, which is equivalent to the recent results from in situ measurements reported by Heymsfield et al. (2002).

\section{Application of the synergetic algorithm to CLARE'98 data}

During CLARE'98 various observing systems were deployed for clouds and radiation at Chilbolton (England) in the autumn of 1998. This ground-based ex- periment (including various meteorological radars and passive microwave observations) was coordinated with flights of three aircraft: the C130 of the Met Office, the Deutschen Zentrum für Luft- und Raumfahrt Falcon, and the Fokker 27 Avion de Recherches Atmosphériques et de Télédétection (ARAT) of the French Institut National des Sciences de l'Univers (INSU). For the purpose of this paper, the joint C130 and ARAT flights are particularly interesting. The instruments used to obtain microphysical data in ice clouds were the PMS 2D-C and 2D-P probes (Francis 1999) mounted aboard the C130, and the ARAT was equipped with the 95-GHz Microwave Radar for Cloud Layer Exploration (MIRACLE) of the University of Wyoming (Pazmany et al. 1994), connected to the dual-beam antenna of CETP (looking alternately at nadir and at 

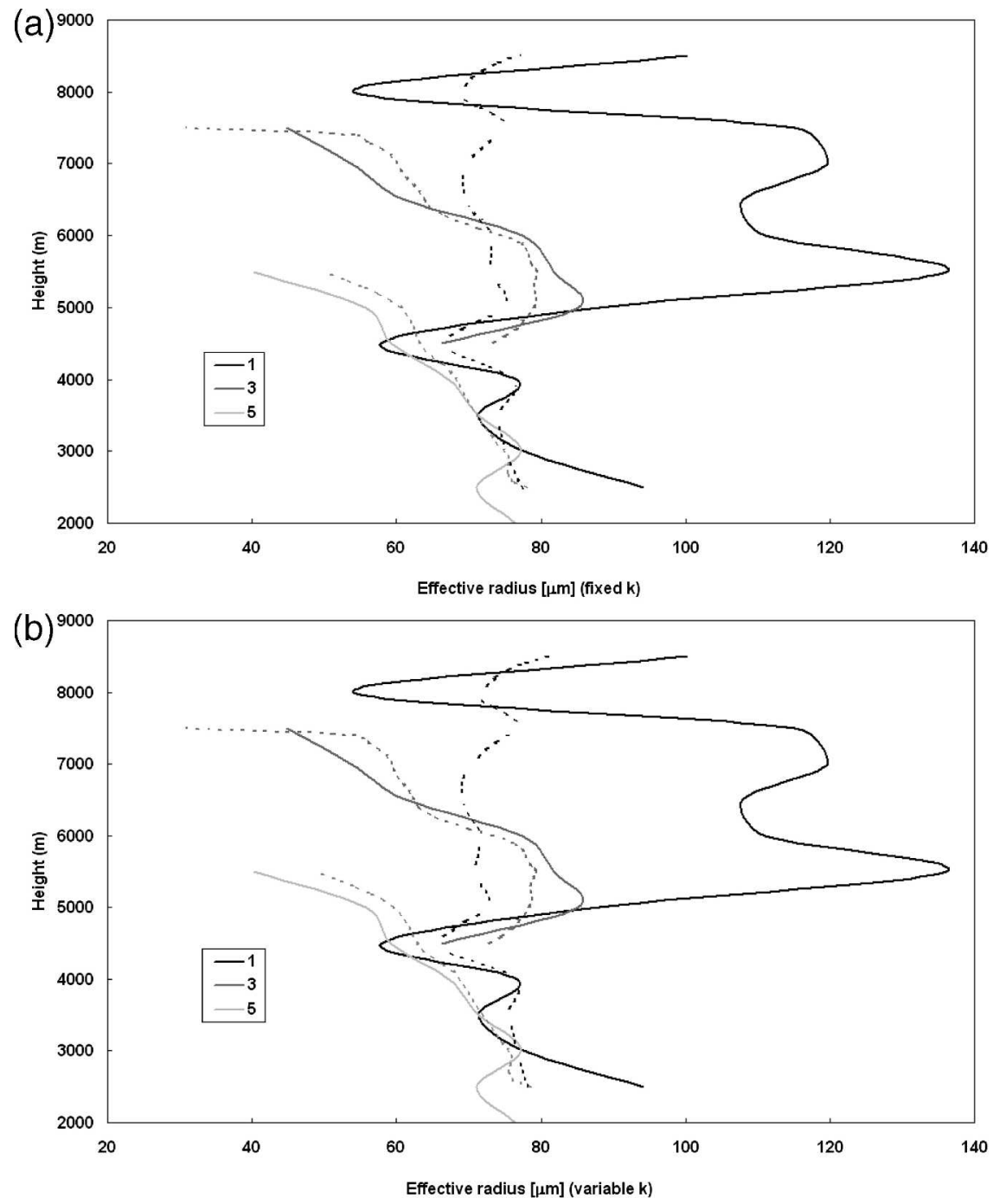

FIG. 5. Realistic (solid lines) and retrieved (dotted lines) visible effective radius derived from the blind test, with (a) fixed $k$ and (b) variable $k$.

about $45^{\circ}$ forward), and with the nadir-looking Lidar Embarqué pour l'étude de l'Atmosphère: Nuages, Dynamique, Rayonnement et cycle de l'Eau (LEANDRE) lidar operating at $0.5 \mu \mathrm{m}$ (Sauvage et al. 1999).

The synergy between radar and lidar is particularly efficient when probing an ice cloud because the penetrations of the radar and the lidar in this type of cloud are generally comparable. The subsequent data analysis is focused on a particular leg (1441-1448 UTC 20 October 1998) for which the ARAT was flying at $4.8-\mathrm{km}$ altitude and the C130 was flying in cloud at $4.6-\mathrm{km}$ altitude along the same leg.

Figure 7 shows measurements provided both by the radar (top panel) and the lidar (bottom panel). An iced cloud is observed between longitudes $1.95^{\circ}$ and $1.65^{\circ} \mathrm{W}$ above approximately $3.2 \mathrm{~km}$. Because of good coordi- nation between the two aircraft, a very satisfactory coincidence in space and time of the ground tracks of the two aircrafts was achieved on this leg. Between longitudes $2^{\circ}$ and $1.7^{\circ} \mathrm{W}$ and above $3-\mathrm{km}$ altitude, both instruments (nadir looking) see the same cloud boundaries, and the synergetic algorithm can be efficiently applied. To ensure that the lidar signal is not too noisy, the algorithm is applied by taking into account a minimal value of $\beta_{a}$ (equal to $2 \times 10^{-3} \mathrm{~km}^{-1} \mathrm{sr}^{-1}$ ) for determining $r_{0}$. Parameter $r_{0}$ is represented with a white full line on Fig. 7 and with black full lines on Fig. 8.

Figure 8 shows the parameters retrieved by the synergetic algorithm. Values of IWC and $r_{e}$ parameters respectively range from 0.01 to $0.28 \mathrm{~g} \mathrm{~m}^{-3}$ and from 30 to $110 \mu \mathrm{m}$. It appears that the algorithm diverges on the left part of the cloud (between $1.93^{\circ}$ and $1.83^{\circ} \mathrm{W}$ longi- 


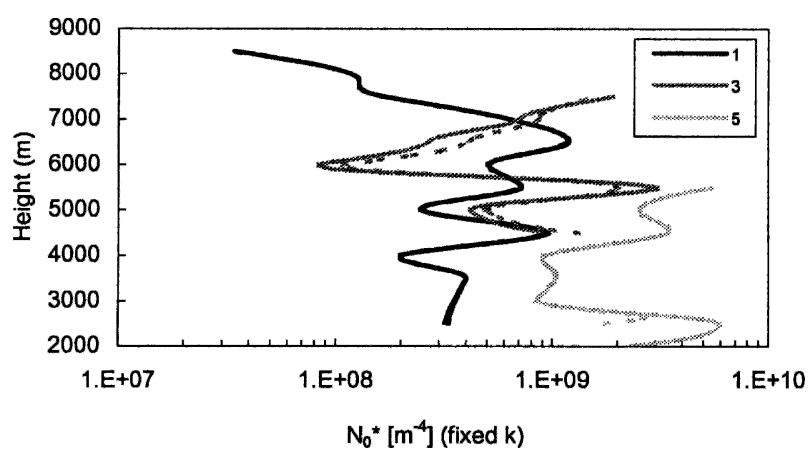

FIG. 6. Realistic (solid lines) and retrieved (dotted lines) $N_{0}^{*}$ derived from the blind test ( $k$ is constant).

tude), where the cloud thickness is less than $300 \mathrm{~m}$ [which is in agreement with the simulation results (Tinel 2002)]. Values obtained in the other part of the cloud are consistent with what is usually observed in ice cloud. Values of $N_{0}^{*}\left(\mathrm{~m}^{-4}\right)$ and $k\left(\mathrm{sr}^{-1}\right)$ range from $10^{8}$ to $10^{10}$ and from $10^{-3}$ to $10^{-1}$, respectively. Even if there are some errors in the radar measurements, retrieved parameter values are continuous in the part of the cloud where the algorithm converges. A constant value of $N_{0}^{*}$ is assumed below the black line [equal to $N_{0}^{*}\left(r_{0}\right)$ ], which allows retrieval of the other parameters by using the inverse model. This assumption is realistic because of the small thickness of the cloud layer.

Figure 9 shows time series of the parameters retrieved by the synergetic algorithm $\left(Z, \mathrm{IWC}, r_{e}, \alpha\right.$, and $N_{0}^{*}$ ) along the ARAT track at the height of $4.48 \mathrm{~km}$. As in Fig. 7, values of IWC and $r_{e}$ are consistent with what

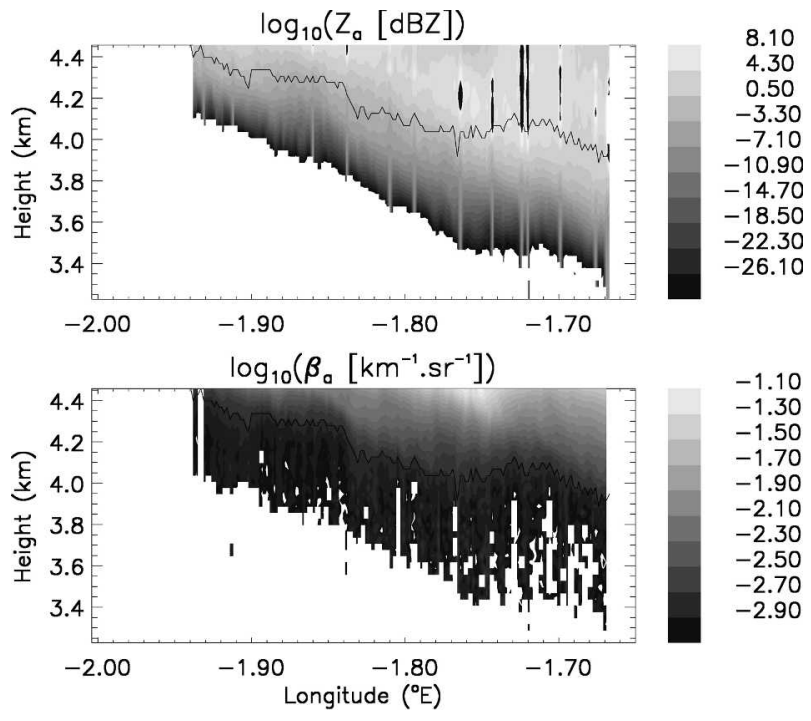

FIG. 7. (top) MIRACLE radar apparent reflectivity and (bottom) LEANDRE lidar apparent backscattering coefficient during CLARE'98 for 1441-1448 UTC 20 Oct 1998.

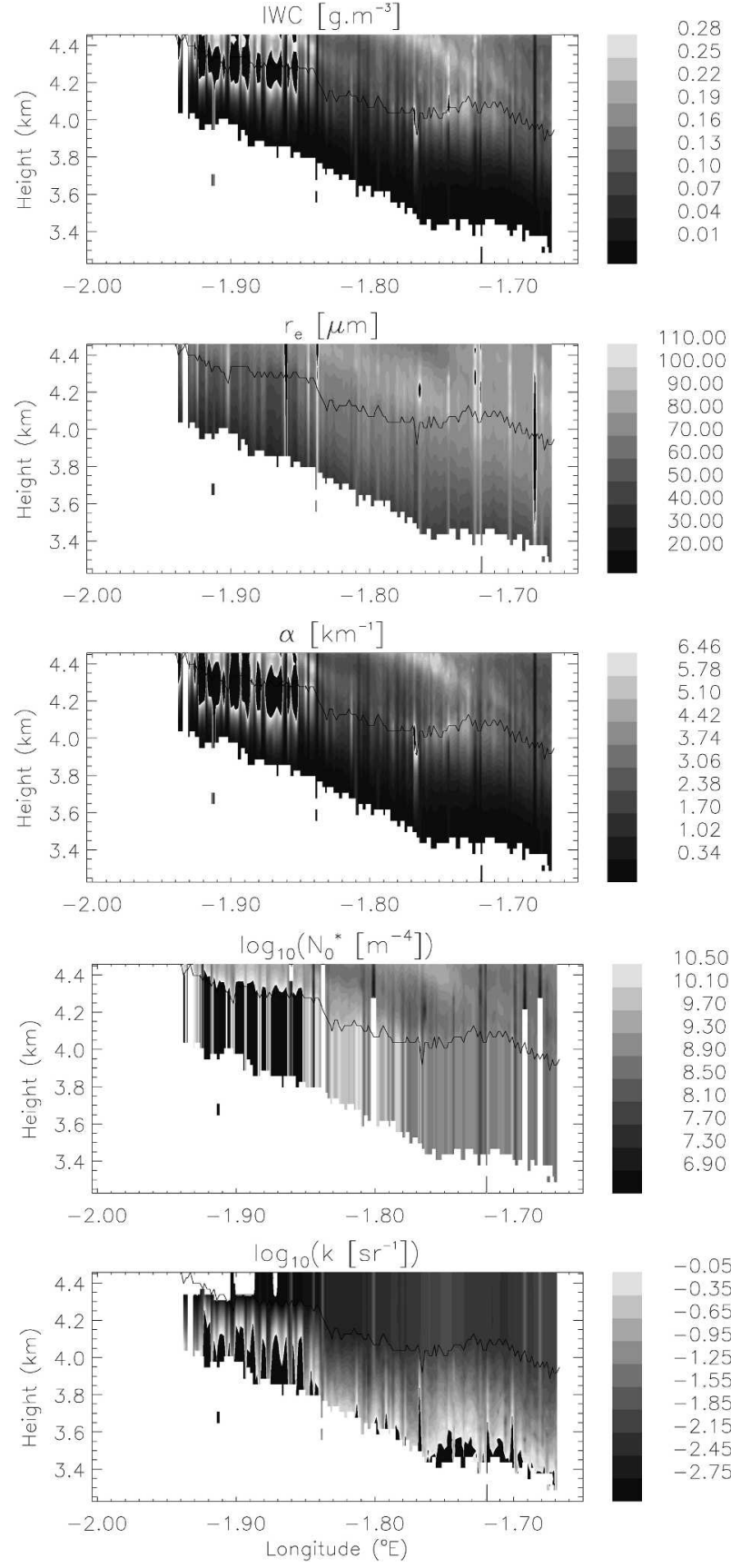

FIG. 8. Vertical cross section of various parameters retrieved with the synergetic algorithm (CLARE'98, at 1441-1448 UTC 20 Oct 1998). From top to bottom: IWC, effective radius $r_{e}$, lidar extinction $\alpha$, normalization parameter $N_{0}^{*}$, and lidar ratio $k$.

is usually observed in ice clouds (mean value of 0.2 $\mathrm{g} \mathrm{m}^{-3}$ for IWC, and values ranging from 65 to $100 \mu \mathrm{m}$ for $r_{e}$ ). Parameters are compared with in situ microphysical parameters calculated by P. Francis (1999, personal communication; represented by dotted lines). The agreement between radar/lidar retrievals and in 

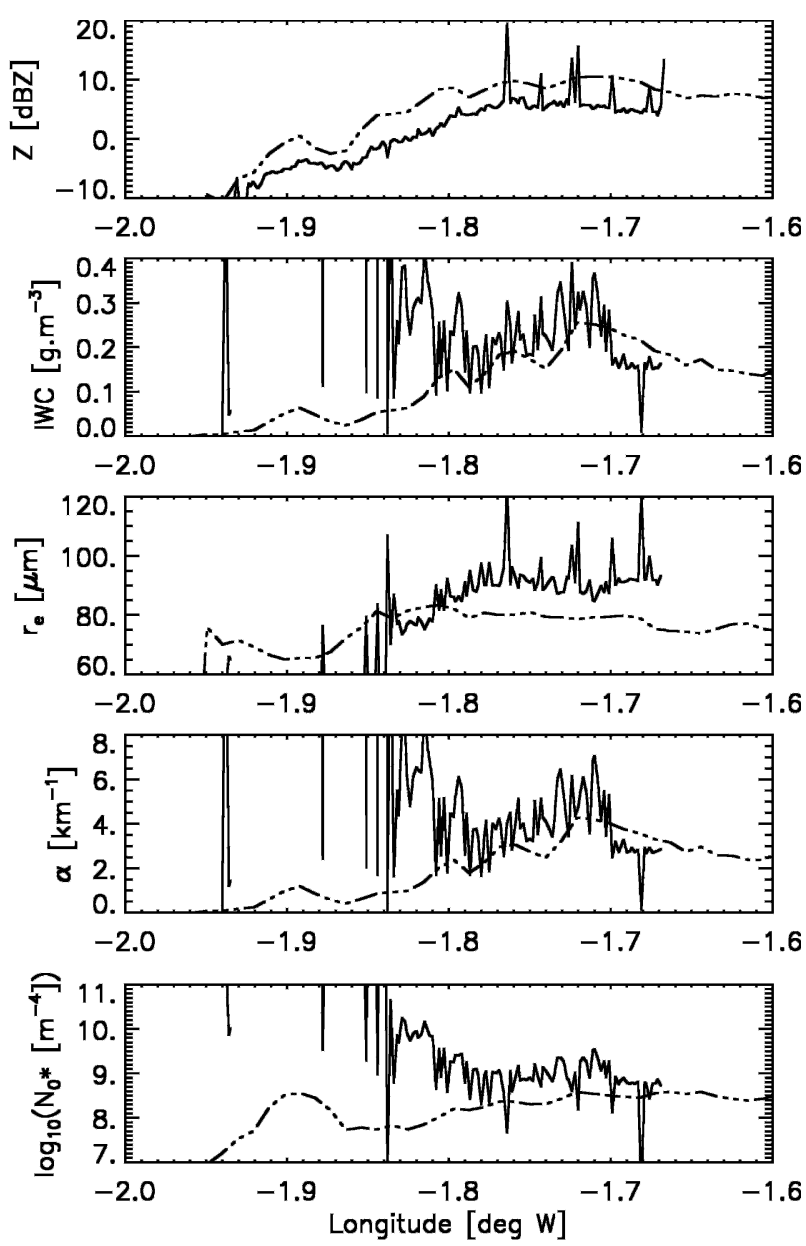

FIG. 9. Along-track evolution at $4.48 \mathrm{~km}$ during CLARE'98 experiment (1441-1448 UTC 20 Oct 1998). From top to bottom: radar reflectivity $Z_{e}$, IWC, $r_{e}$, extinction coefficient $\alpha$, and PSD parameter $N_{0}^{*}$. Solid lines: synergetic algorithm; dotted lines: in situ measurements.

situ measurements is good between $1.84^{\circ}$ and $1.65^{\circ} \mathrm{W}$. Beyond $1.84^{\circ} \mathrm{W}$, the divergence of the algorithm, as mentioned before, is observed because of the strong lidar attenuation into the dense cloud part. To get rid of this divergence, another version of the algorithm that assumes a constant $N_{0}^{*}$ value within the cloud, which substantially simplifies Eq. (19), has been applied. This assumption is realistic in this case because the cloud layer thickness is small, but it could not generally be used with a deeper cloud layer. Figure 10 represents the parameters obtained using this assumption. Retrieved values are similar to those retrieved by the profiling algorithm when it does not diverge and are close to the in situ measurements between $1.93^{\circ}$ and $1.83^{\circ} \mathrm{W}$ longitude. This result validates, in particular, the assumption of a constant $N_{0}^{*}$ profile for small cloud-layer thickness (less than $500 \mathrm{~m}$; Tinel 2002).
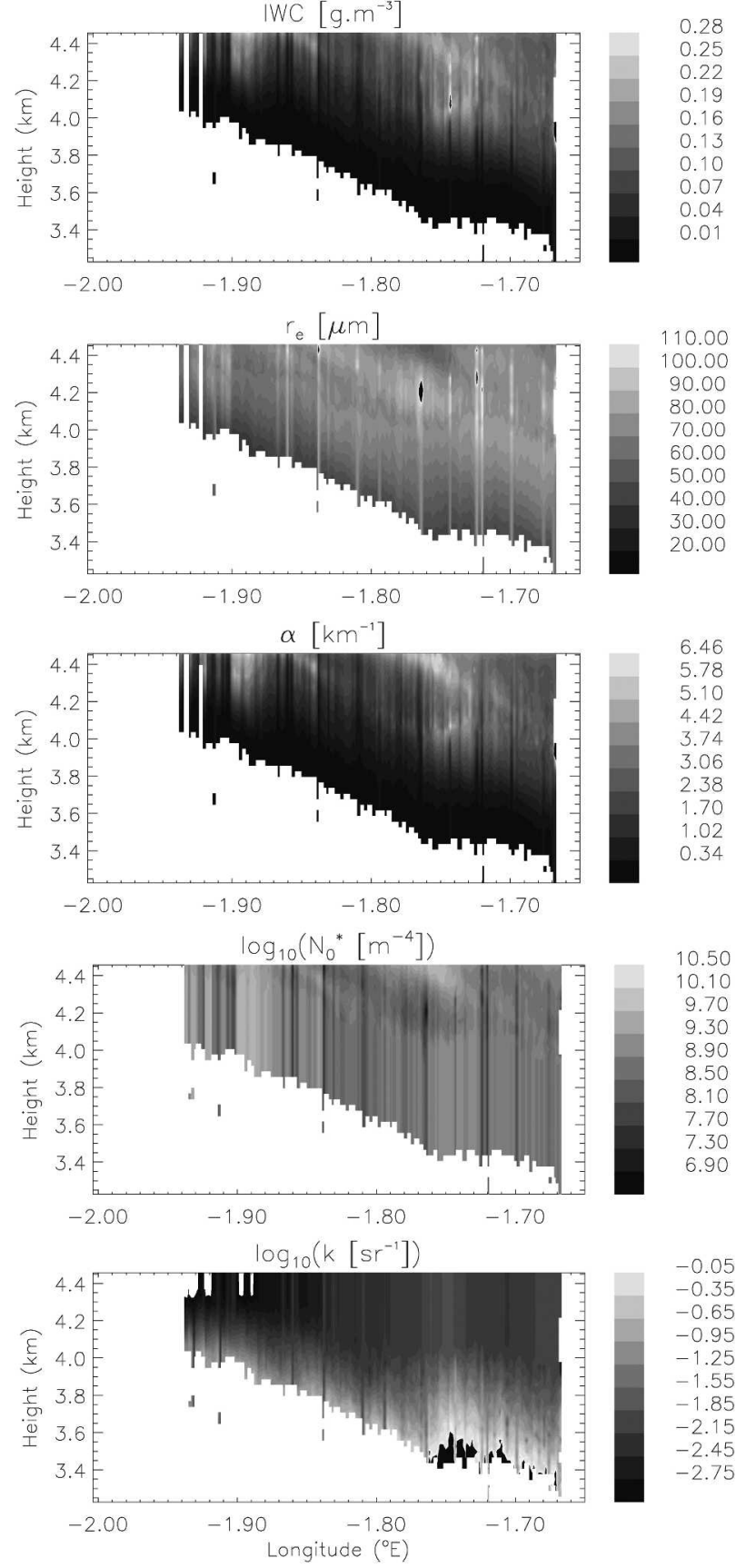

FIG. 10. Vertical cross section of various parameters retrieved with the synergetic algorithm for $N_{0}^{*}$ constant (CLARE'98, at 1441-1448 UTC 20 Oct 1998). From top to bottom: IWC, $r_{e}$, lidar extinction $\alpha$, normalization parameter $N_{0}^{*}$, and lidar ratio $k$.

\section{Conclusions}

The potential of cloud radar and lidar combination on the same platform is very promising. We have presented in this paper a new synergetic algorithm, the formulation of which relies on a normalization param- 
eter $N_{0}^{*}$. The use of this parameter allows us to take into account the natural variability of particle concentration in clouds. Simulation tests (Tinel 2002) and blind tests have shown the capacity of the algorithm to retrieve cloud parameters (with relative errors of less than 10\% for optical extinction and ice water content). This algorithm has then been applied to real data from CLARE'98, and good agreement between the retrieved and in situ parameters has been obtained.

The aim of this paper was to describe a first version of a new and original radar-lidar algorithm. Because we assume that concentrations in large and small crystals are related, the application of the algorithm is limited to the retrieval of effective radius larger than 20 $\mu \mathrm{m}$ and smaller than $200 \mu \mathrm{m}$. Because this algorithm requires a substantial lidar return, this technique is applied to high clouds where the lidar signal is strong enough to penetrate deep into the clouds. This condition means that radar reflectivities should not excess 20 $\mathrm{dBZ}$ (for a W-band radar). Effects of precipitation would not affect the radar signal too much but would often totally extinguish lidar signal, which is why this algorithm applies to nonprecipitating clouds. Equivalent radar/lidar methods exist for drizzle and liquid clouds (Baedi et al. 2000; O'Connor et al. 2004), and a companion version of this algorithm can be imagined for lightly precipitating clouds (such as the drizzling part of stratocumulus), where a lidar return is available. However, such an algorithm requires a specific inverse model. At this point, further developments of this algorithm should be directed toward the following:

- The segmentation of the analysis in the conditions in which different types of cloud are met along the beam should be investigated. For example, the leg just before the studied case in this paper was in a cloud with a thin supercooled layer embedded within the deeper ice stratus, and preliminary work has already been done by Tinel (2002). We also often meet cases with multilayered clouds that have to be processed separately. Both configurations could be accounted for in the algorithm. For mixed-phase clouds, the radar will be essentially sensitive to the ice while the lidar will be essentially sensitive to the liquid water. This phenomenon is another complementary aspect of the radar-lidar combination that needs to be explored (Hogan et al. 2003).

- The analysis should be extended to other microphysical datasets to evaluate our inverse model and to document possible systematic variations of the $N_{0}^{*}$ parameter with altitude or normalized cloud height.

- The interest of using the terminal fall velocities retrieved from the radar Doppler measurements (e.g.,
Protat et al. 2002) as an additional constraint to the algorithm should be investigated.

- The lidar measurements should be corrected for multiple scattering, which is likely to contribute in a significant manner in some ice clouds. An analytical procedure proposed by Eloranta (1998) is now being tested in the algorithm.

- The Mie effects in the inverse model should be accounted for more precisely. Such an accounting may be done with a parameterization by $D_{m}$ of the coefficients of the power-law relationships.

- The information from microphysical probes on diameter and area, and not only on area, should be taken into account. The use of various density laws for the establishment of the inverse model may affect the IWC retrievals by a factor of almost 2 . This effect is being taken into account through an extensive analysis of microphysical in situ measurements in both tropical and midlatitude regions (Delanoë et al. 2005).

The ground-based version of this algorithm has already been implemented. It is being systematically applied to the large ground-based database collected from three European cloud remote sensing stations [Cabauw, Netherlands, Site Instrumental de Recherche par Télédétection (SIRTA) in Palaiseau, France, and Chilbolton] that are equipped with cloud radar and lidar in the framework of the European "CloudNET" project.

The spaceborne application of this algorithm obviously needs to be explored soon. The adaptation of this version of the algorithm would require that simulations of the radar and lidar measurements from space be performed, with evaluation of the skills of the algorithms in this spaceborne configuration.

Acknowledgments. The authors are grateful to Peter Francis at the Met Office and Dagmar Nagel at GKSS for providing in situ microphysical data. This research was funded by CloudNET project (EVK2-CT200000065) and ESA (15741/01/NL/SF). ESA, INSU, and CNES are acknowledged for their financial support of our participation in the CLARE'98 and CARL'99 field experiments.

\section{REFERENCES}

Ansmann, A., U. Wandinger, M. Riebesell, C. Weitkamp, and W. Michaelis, 1992: Independent measurements of extinction and backscatter profiles in cirrus clouds by using a combined Raman elastic-backscatter lidar. Appl. Opt., 3, 7113-7131.

Baedi, R. J. P., J. J. M. de Wit, H. W. J. Russchenberg, J. S. Erkelens, and J. P. V. Poiares Baptista, 2000: Estimating effective radius and liquid water content from radar and lidar 
based on the CLARE'98 data-set. Phys. Chem. Earth, 25, 1057-1062.

Battan, L. J., 1973: Radar Observations of the Atmosphere. University of Chicago Press, $324 \mathrm{pp}$.

Cess, R. D., and Coauthors, 1990: Intercomparison and interpretation of climate feedback processes in 19 atmospheric general circulation models. J. Geophys. Res., 95, 16 601-16 615. , and Coauthors, 1996: Cloud feedback in atmospheric general circulation models: An update. J. Geophys. Res., 101, 12 791-12 794.

Delanoë, J., A. Protat, J. Testud, D. Bouniol, A. J. Heymsfield, A. Bansemer, P. R. A. Brown, and R. M. Forbes, 2005: Statistical properties of the normalized ice particle size distribution. J. Geophys. Res., 110, D10201, doi:10.1029/ 2004JD005405.

Donovan, D. P., and A. C. A. P. van Lammeren, 2001: Cloud effective particle size and water content profile retrievals using combined lidar and radar observations. Part 1: Theory and simulations. J. Geophys. Res., 106, 27 425-27 448.

— content profile retrievals using combined lidar and radar observations. Part 2: Comparison with IR radiometer and insitu measurements of ice clouds. J. Geophys. Res., 106, 27 449-27 464.

Eloranta, E. W., 1998: A practical model for the calculation of multiply scattered lidar returns. Appl. Opt., 37, 2464-2472.

Flamant, P. H., V. Noël, H. Chepfer, M. Quante, O. Danne, V. Giraud, and J. Pelon, 2000: Particle sizes in cirrus cloud during the Carl'99 campaign: 29 April and 14 May case studies. Extended Abstracts, Int. Radiation Symp., St. Petersburg, Russia, Research Institute of Physics.

Francis, P. N., 1999: A summary of the clouds microphysics data collected during CLARE'98 by the UKMO C-130 aircraft. Proc. ESTEC Int. Workshop WPP-170, Noordwijk, Netherlands, ESTEC, 13-14.

—- A. Jones, R. W. Saunders, K. P. Shine, A. Slingo, and Z. Sun, 1994: An observational and theoretical study of the radiative properties of cirrus: Some results from ICE'89. Quart. J. Roy. Meteor. Soc., 120, 809-848.

_, P. Hignett, and A. Macke, 1998: The retrieval of cirrus cloud properties from aircraft multi-spectral reflectance measurements during EUCREX'93. Quart. J. Roy. Meteor. Soc., 124, 1273-1291.

Heymsfield, A. J., and J. L. Parrish, 1978: A computational technique for increasing the effective sample volume of the PMS two-dimensional particle size spectrometer. J. Appl. Meteor., 17, 1566-1571.

, A. Bansemer, P. R. Field, S. L. Durden, J. L. Stith, J. E. Dye, W. Hall, and C. A. Grainger, 2002: Observations and parameterizations of particle size distributions in deep tropical cirrus and stratiform precipitating clouds: Results from in situ observations in TRMM field campaigns. J. Atmos. Sci., 59, 3457-3491.

Hitschfeld, W., and J. Bordan, 1954: Errors inherent in the radar measurements of rainfall at attenuating wavelengths. J. Meteor., 11, 58-67.

Hogan, R. J., P. N. Francis, H. Flentje, A. Illingworth, M. Quante, and J. Pelon, 2003: Characteristics of mixed-phase clouds. Part 1: Lidar, radar and aircraft observations from CLARE'98. Quart. J. Roy. Meteor. Soc., 129, 2089-2116.

Illingworth, A. J., and all CLARE Participants, 1999: Overview of the flights and datasets. CLARE'98 Cloud Lidar and Radar
Experiment, Proc. ESTEC Int. Workshop WPP-170, Noordwijk, Netherlands, ESTEC, 17-24

Intrieri, J. M., W. L. Eberhard, and G. L. Stephens, 1990: Preliminary comparison of lidar and radar backscatter as a means of assessing cirrus radiative properties. Preprints, Seventh Conf. on Atmospheric Radiation, San Francisco, CA, Amer. Meteor. Soc., 354-356.

—, G. L. Stephens, W. L. Eberhard, and T. Uttal, 1993: A method for determining cirrus cloud particles sizes using lidar and radar backscatter technique. J. Appl. Meteor., 32, 10741082.

Klett, J. D., 1981: Stable analytical inversion solution for processing lidar returns. Appl. Opt., 20, 211-220.

Kumagai, H., H. Horie, H. Kuroiwa, H. Okamoto, and S. Iwasaki, 2000: Retrieval of cloud microphysics using $95-\mathrm{GHz}$ cloud radar and microwave radiometer. Proc. SPIE, 4152, 364-371.

Lhermitte, R., 1987: A 94-GHz doppler radar for cloud observations. J. Atmos. Oceanic Technol., 4, 36-48.

Mace, G. G., T. P. Ackerman, P. Minnis, and D. F. Young, 1998a: Cirrus layer microphysical properties derived from surfacebased millimeter radar and infrared interferometer. J. Geophys. Res., 103, 23 207-23 216.

- K. Sassen, S. Kinne, and T. P. Ackermann, 1998b: An examination of cirrus cloud characteristics using data from millimetre wave radar and lidar: The 24 April SUCCESS case study. Geophys. Res. Lett., 25, 1133-1136.

Matrosov, S. Y., T. Uttal, J. B. Snider, and R. A. Kropfli, 1992: Estimation of ice clouds parameters from ground-based infrared radiometer and radar measurements. J. Geophys. Res., 97, $11567-11574$

McFarquhar, G. M., and A. J. Heymsfield, 1998: The definition and significance of an effective radius for ice clouds. J. Atmos. Sci., 55, 2039-2052.

O'Connor, E. J., R. J. Hogan, and A. J. Illingworth, 2005: Retrieving stratocumulus drizzle parameters using Doppler radar and lidar. J. Appl. Meteor., 44, 14-27.

Okamoto, H., S. Iwasaki, M. Yasui, H. Horie, H. Kuroiva, and H. Kumagai, 2003: An algorithm, for retrieval of cloud microphysics using 95-GHz cloud radar and lidar. J. Geophys. Res., 108, 4226, doi:10.1029/2001JD001225.

Paltridge, G. W., 1974: Global cloud cover and earth surface temperature. J. Atmos. Sci., 31, 1571-1576.

Pazmany, A. L., R. E. McIntosh, R. D. Kelly, and G. Vali, 1994: An airborne $95 \mathrm{GHz}$ dual polarization radar for cloud studies. IEEE Trans. Geosci. Remote Sens., 1, 731-739.

Pelon, J., and Coauthors, 2001: Final report of investigation of cloud by ground-based and airborne radar and lidar (CARL). European Commission DGXII Contract PL970567, 39 pp.

Protat, A., C. Tinel, and J. Testud, 2002: Dynamic properties of water and ice clouds from dual-beam airborne cloud radar data: The Carl'2000 and Carl'2001 validation campaigns. Proc. of the 11th Cloud Physics Conf., Ogden, UT, Amer. Meteor. Soc., CD-ROM, P5.18.

Riedi, J., M. Doutriaux-Boucher, P. Goloub, and P. Couvert, 2000: Global distribution of cloud top phase from POLDER/ ADEOS I. Geophys. Res. Lett., 27, 1707-1710.

Sauvage, L., H. Chepfer, V. Trouillet, P. H. Flamant, G. Brogniez, J. Pelon, and F. Albers, 1999: Remote sensing of cirrus radiative properties during EUCREX'94. Case study of 17 April 1994. Part 1: Observations. Mon. Wea. Rev., 127, 504519 .

Testud, J., P. Amayenc, X. Dou, and T. Tani, 1996: Tests of rain profiling algorithms for a spaceborne radar using raincell 
models and real data precipitation fields. J. Atmos. Oceanic Technol., 13, 426-453.

— , S. Oury, R. A. Black, P. Amayenc, and X. Dou, 2001: The concept of "normalized" distribution to describe raindrop spectra: A tool for cloud physics and cloud remote sensing. $J$. Appl. Meteor., 40, 1118-1140.

Tinel, C., 2002: Restitution des propriétés microphysiques et radiatives des nuages froids et mixtes à partir des données du système RALI (Radar-Lidar) (Retrieval of microphysical and radiative parameters of ice and mixed-phased clouds from the RALI system). Ph.D. thesis, University Paris 7, $237 \mathrm{pp}$.

, J. Testud, A. Guyot, and K. Caillault, 2000: Cloud param- eter retrieval for combined remote sensing observations. Phys. Chem. Earth, 25, 1063-1067.

Uttal, T., R. A. Kropfli, W. L. Ebenhard, and J. M. Intrieri, 1990: Observations of mid-latitude, continental cirrus clouds using a $3.2 \mathrm{~cm}$ radar: Comparisons with $10.6 \mu \mathrm{m}$ lidar observations. Preprints, Seventh Conf. on Atmospheric Radiation, San Francisco, CA, Amer. Meteor. Soc., 349-353.

Van de Hulst, H. C., 1957: Light Scattering by Small Particles. John Wiley and Sons, $470 \mathrm{pp}$.

Wang, Z., and K. Sassen, 2002: Cirrus cloud microphysical property retrieval using lidar and radar measurements. Part 1: Algorithm description and comparison with in situ data. $J$. Appl. Meteor., 41, 218-229. 